\title{
Circadian Biometric Recorder
}

National Cancer Institute

\section{Source}

National Cancer Institute. Circadian Biometric Recorder. NCI Thesaurus. Code C155848.

A proprietary device that uses a thermal differential detection system to detect and record abnormal circadian cellular temperature changes, including those associated with breast cancer tumor infusion. 